\title{
A NEUROLOGIC EVALUATION OF THE CUTANEOUS HISTAMINE REACTION ${ }^{1}$
}

\author{
BY IRVING S. COOPER ${ }^{2}$
}

(From the United States Naval Hospital, Oakland, California)

(Submitted for publication September 9, 1949; accepted, December 12, 1949)

Spiess (1) was the first author to suggest that peripheral vasodilatation following stimulation of the skin is due to a nervous reflex. On the basis of production of reflex dilatation of conjunctival vessels, following division of the sensory nerve to that area in a dog, Bruce (2) postulated that this reflex was mediated entirely by ramifying axones of sensory nerves. He did not consider, however, the possible effects of antidromic injury impulses or of pseudoreflexes in a distal nerve segment (3), either of which can produce dilatation of peripheral arterioles (4). Mïller (5) investigated the cutaneous vascular reaction to injury by stroking the skin of human subjects with a sharp instrument. Because he observed the appearance of reflex erythema at a considerable distance from the site of stimulation, and because he noted a deficiency of spreading erythema in several dermatomes below the level of spinal cord transection in paraplegic patients, Müller concluded that the spreading flush is mediated by a spinal reflex arc. He stressed the fact that the spreading flare is not affected in cases of "incomplete paraplegia."

Lewis (6) and Lewis and Grant (7) described the triple response of cutaneous vessels to injury; this response consists of an initial red reaction, spreading flare, and localized wheal. Lewis (8) stated that the depression of the spreading flare in cases of paraplegia, as reported by Müller (5), "is not invariable." However, the illustrative case of paraplegia cited by Lewis may have represented an incomplete transection of the spinal cord, inasmuch as the cord injury was due to pressure by an abdominal aortic aneurysm. The hypothesis that the spreading flare phase of the triple response was induced solely by means of an axone reflex was championed by Lewis (8) as well as by Breslauer (9) and Loeser (10).

\footnotetext{
1 Presented before the Minnesota Society of Neurology and Psychiatry, May, 1949.

2 Present address : 905 14th Avenue, N.E., Rochester, Minnesota.
}

The present study deals with the neurologic basis for the spreading flare.

\section{MATERIAL AND METHODS}

Paired intradermal injections of $0.1 \mathrm{cc}$. of histamine in $1: 5,000$ and $1: 10,000$ aqueous dilutions were made into anesthetic and normally sensitive cutaneous areas of 50 young adult males who presented lesions at various levels of the nervous system. The diameter of the initial red reaction was measured 30 seconds after injection, and that of the spreading flare and wheal five minutes after injection. Whenever the reaction in an anesthetic area differed from that in its control site, a "stroke" reaction was produced and similar measurements were made.

The categories of neurologic lesions included in this study were: 1) incomplete transection of a peripheral nerve, 12 cases; 2) complete transection of a peripheral nerve, 13 cases; 3) disease of the anterior horn cells, three cases; 4) complete transection of the spinal cord, 10 cases; 5) incomplete transection of the spinal cord, four cases; 6) surgical lesions of the sympathetic nervous pathways, three cases; 7) lesion of the anterior spinal commissure, one case; and 8) intracranial lesions producing profound coma, two cases. Two cases of hysterical anesthesia were also included.

\section{RESULTS}

\section{Incomplete Transection of a Peripheral Nerve}

In areas of the skin rendered hypo-esthetic by partial transection of a peripheral nerve the primary flare, the wheal and the secondary flare were of the same dimensions and time relationships as those appearing on a normal cutaneous zone. There was no indication, by this clinical method of testing, that partial transection of a nerve interfered either qualitatively or quantitatively with the secondary flushing reaction.

\section{Complete Transection of a Peripheral Nerve}

All transections were of at least three months' duration. The initial red reaction and wheal were identical in anesthetic and control areas. However, in the anesthetic skin there was no spreading flare. This would substantiate all previous 
hypotheses which ascribed the spreading flare to a neurogenic mechanism mediated by the peripheral nervous supply.

\section{Disease of the Anterior Horn Cells}

In three patients with severe poliomyelitis of at least three months' duration, in whom one or more extremities appeared clinically to be devoid of anterior horn cell function, but without cutaneous sensory loss, all three elements of the triple response on the skin of the paralyzed extremity were identical in size and time of appearance with those on control areas. This observation suggests that the final common pathway does not play a significant role in the neurogenic mechanism involved in the spreading flare.

\section{Complete Transection of the Spinal Cord}

This group included only those cord transections verified by surgical exploration, or cases in which the transection appeared complete, clinically, for at least 12 months. The spinal cord lesions in individual cases were distributed between the eighth cervical and 12th thoracic segments. In nine of the 10 cases the spreading flare was absent below the level of transection, while in the remaining case it was markedly decreased in size as compared to the control response. The initial red reaction and wheal were identical in anesthetic and control zones (Figures 1 and 2 ). The triple response following a stroke stimulus corresponded to the reaction following histamine (Figure 3 ). One patient in this group proved to be sensitive to histamine and his response serves to exemplify the reaction in cases of complete transection of the cord.

Paired intradermal injections of $1: 5,000$ aqueous dilution of histamine were made into the anesthetic skin of the right thigh and the normal skin of the right forearm of a 21-year-old white male who had experienced a complete transection of the cord, at the sixth thoracic segment, 14 months previously. After 30 seconds the initial red reaction on the thigh measured 6 by $6 \mathrm{~cm}$. and that on the forearm measured 5 by $6 \mathrm{~cm}$. At the end of five minutes the erythematous area on the thigh still measured 6 by $6 \mathrm{~cm}$. whereas the reddened zone on the forearm had spread to dimensions of
27.5 by $8 \mathrm{~cm}$. and involved the entire volar surface of the forearm. At this time the patient complained of a flushed face and a moderately intense headache.

These observations suggest that suprasegmental centers may be essential to the neurogenic mechanism of the spreading flare.

\section{Incomplete Transection of the Spinal Cord}

In patients with incomplete transection of the cord all phases of the histamine response were similar to those in control areas. This was true even in cases in which superficial sensation was seriously impaired or absent but in which deep pressure sensation was appreciated.

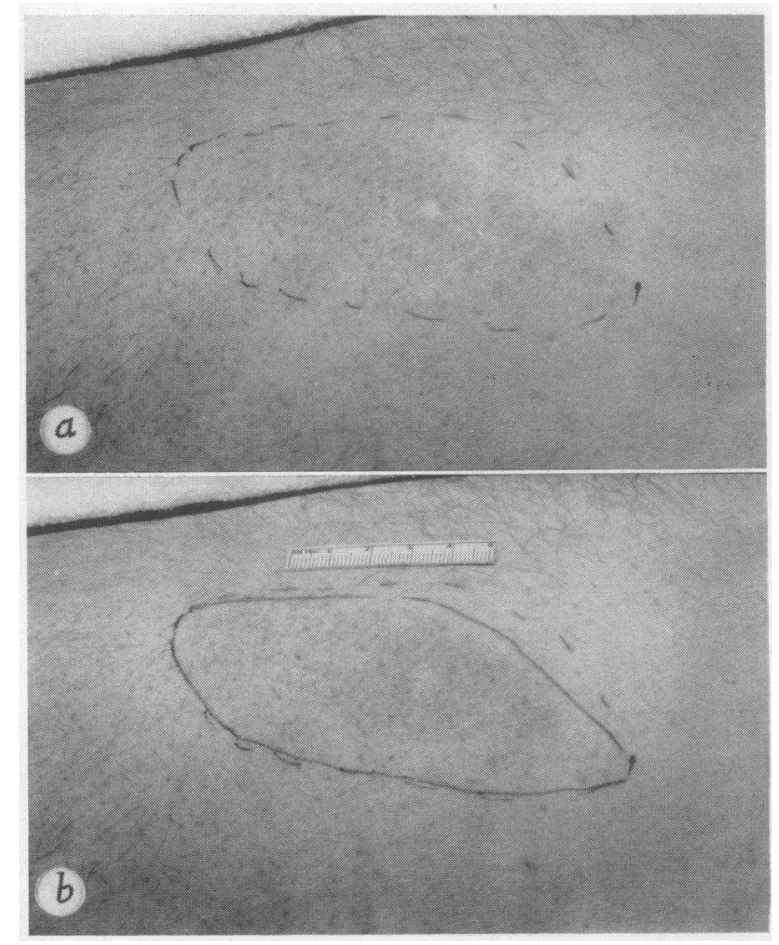

Fig. 1a. Area of Primary Flush Following Intradermal Injection of $1: 10,000$ Solution of Histamine Below the Level of a Complete Transection of the Spinal Cord

The extent of the primary flare is indicated by a broken line.

b. Same Area Five Minutes After the Intradermal. Injection of Histamine

The extent of the flare at this time is indicated by the unbroken line. There has been no secondary extension of the flare. Compare this photograph with Figure $2 b$. 


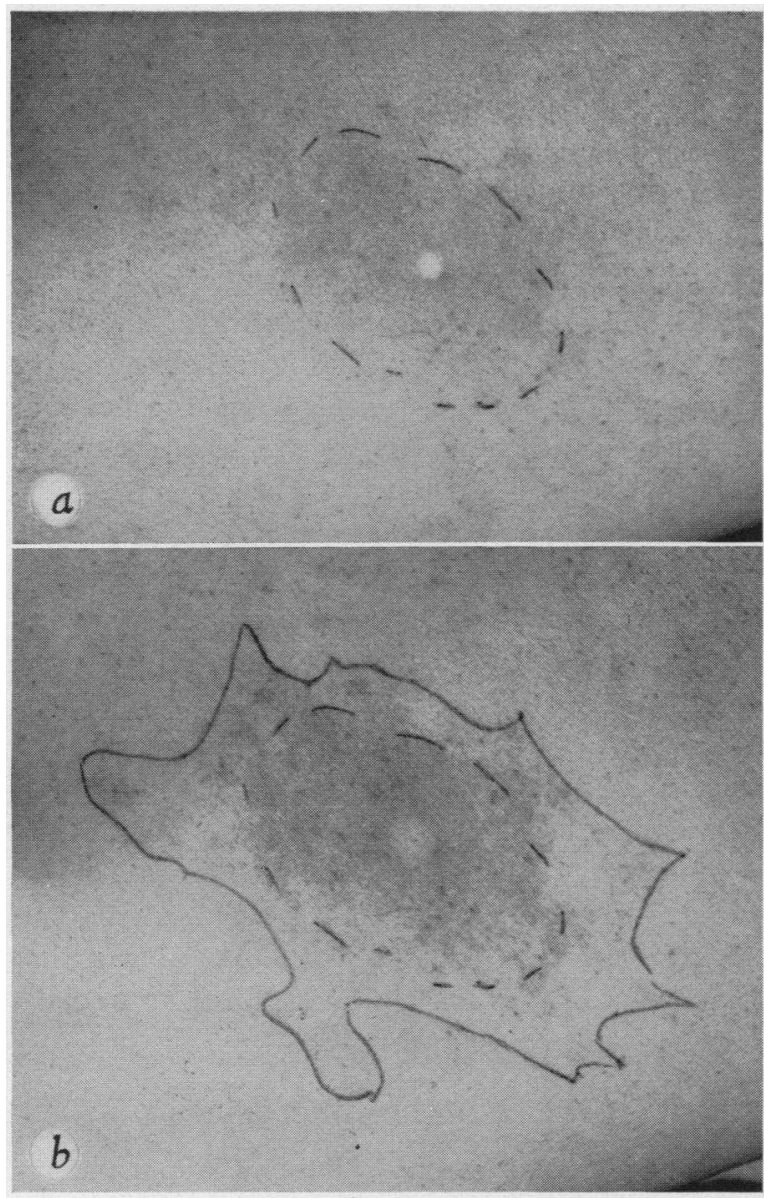

Fig. 2a. Primary Flush Following the Intradernal Injection of Histamine in the Normal or "Control Zone," Above the Level of Spinal Cord Transection (From the same patient as in Figure 1)

The broken line indicates the extent of the flare 30 seconds after the injection.

b. The Spreading Flush or Secondary Flare in the Control Zone Is Indicated, at the End of Five Minutes, by the Unbroken Line.

\section{Lesions of the Peripheral Sympathetic Nervous Pathways}

The cutaneous vascular response to histamine was identical on the thighs of sympathectomized extremities and on nonsympathectomized extremities. The test areas were noted to be free of sweating at the time of this study, whereas the control areas demonstrated normal sweating. These observations suggest that the peripheral sympathetic nerve supply to the lower extremi- ties is not essential to the mechanism of the spreading flare.

\section{Lesion of the Anterior Spinal Commissure}

The patient in this category had a surgically verified syringomyelic cavity of the cervical cord, and was unable to perceive pain or temperature variation over dermatomes $\mathrm{C}-5$ through $\mathrm{T}-2 \mathrm{bi}$ -

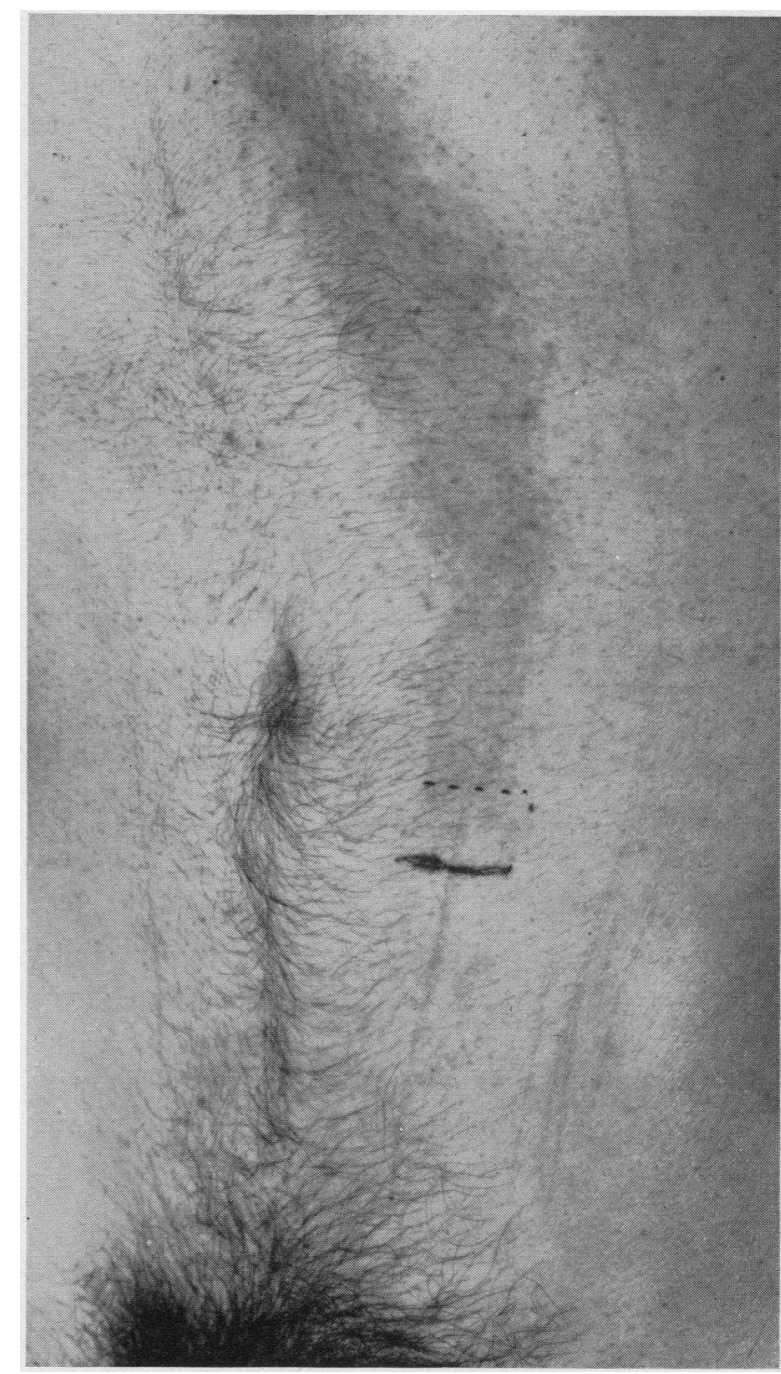

Fig. 3. The Flare Surrounding a Line Made With a Sharp Needle on the Skin of the Same Patient as Figures 1 and 2

The secondary flare is present only above the level of the spinal cord transection and overlaps approximately one dermatome below the level of anesthesia indicated by broken line. Below this level the line made by the needle may be seen but no flare is visible. This photograph was taken five minutes after application of the stimulus. 
laterally. The triple response in the analgesic areas was identical with that in normal control zones. Consequently, the central spinal fibers subserving pain would not appear to be essential to the neurologic mechanism of the spreading flare.

\section{Intracranial Lesions}

The two cases in this category are herein briefly reported.

A 22-year-old white male was examined while in deep coma due to an obstruction of the aqueduct of Sylvius which had produced hydrocephalus (diagnosis confirmed by necropsy). An intradermal injection of $1: 10,000$ solution of histamine into the anterior cutaneous surface of each thigh was followed by the appearance of a flare which measured 10.5 by $7.5 \mathrm{~cm}$. after 30 seconds but did not increase in size thereafter.

This observation substantiates Müller's report that certain central lesions result in a more rapid appearance of the spreading erythematous reaction (5).

A 19-year-old white male was examined several hours after he had incurred a concussive intracranial injury, at which time he was comatose but did react to painful stimuli. Histamine in $1: 5,000$ solution was injected intradermally on the anterior surface of the right thigh. The initial red reaction measured 4.2 by $3.8 \mathrm{~cm}$. and the final flare measured 6.3 by $4.2 \mathrm{~cm}$. A similar injection ten days later, at which time the patient was in a state of decerebrate rigidity, resulted in an initial red reaction measuring 3 by $2.7 \mathrm{~cm}$., but no spreading flare was observed.

Inasmuch as a state of decerebrate rigidity indicates independence of the lower nervous centers from all centers superior to the pons (11), the successive tests carried out on this patient suggest that one or more centers cephalad to the pons affect the spreading flare phase of the triple response.

\section{Hysteria}

The triple response in a cutaneous zone from which sensation is not perceived due to hysteria is identical with that in a normal control area.

\section{COMMENT}

The observations reported above suggest that the axone reflex hypothesis of the spreading flare be re-evaluated. The failure of the spreading flare to appear in dermatomes below the level of complete transection of the spinal cord, the rapid appearance of the spreading flare in a case of cerebral involvement, and the disappearance of the spreading flare following isolation of spinal centers from nervous influences cephalad to the pons cannot be readily explained on the basis of the axone reflex theory alone. Likewise, the isolated spinal reflex arc cannot subserve this reflex vasodilatation. It is suggested, therefore, that a suprasegmental reflex arc is concerned in the neurogenic mechanism underlying the secondary flare. It would seem likely that such a center might be located in the diencephalon, which is known to be intimately concerned with peripheral vasodilatation. Moreover, neither the preganglionic sympathetic fibers nor the final common pathway are essential to the spreading flare, and it is suggested that both afferent and efferent impulses in this reflex travel via sensory nerves and dorsal nerve roots (12-14).

This hypothesis does not eliminate a role of the axone reflex in the triple response. It does suggest, however, that the spreading flare, or that component of the flare appearing after 30 seconds, is the result of a central reflex.

\section{SUMMARY AND CONCLUSIONS}

1. The spreading flare phase of the triple response is absent following complete transection of a spinal nerve.

2. The spreading flare is absent or markedly decreased in dermatomes below the level of complete transection of the spinal cord, and following isolation of the cord from nervous centers cephalad to the pons.

3. Neither preganglionic sympathetic pathways nor the final common pathways are essential to the spreading flare.

4. It is suggested that the axone reflex alone cannot subserve the neurogenic mechanism of the spreading flare, and this mechanism may include a suprasegmental reflex arc, the afferent arm of which reaches as high as the diencephalon or higher. The afferent and efferent impulses in this reflex travel via the dorsal nerve roots.

\section{BIBLIOGRAPHY}

1. Spiess, G., Quoted by Bruce, A. N.

2. Bruce, A. N., Úber die Beziehung der sensiblen Nervenendigungen zum Entzündungsvorgang. Arch. f. exper. Path. u. Pharmakol., 1910, 63, 424. 
3. Kugelberg, E., "Injury activity" and "trigger zones" in human nerves. Brain, 1946, 69, 310.

4. Foerster, O., The dermatomes in man. Brain, 1933, $56,1$.

5. Müller, L. R., Studien über den Dermographismus und dessen diagnostische Bedeutung. Deutsche Ztschr. f. Nervenh., 1913, 47, 413.

6. Lewis, T., Vascular reactions of the skin to injury. I. Reaction to stroking; urticaria factitia. Heart, 1924, 11, 119.

7. Lewis, T., and Grant, R. T., Vascular reactions of the skin to injury. II. The liberation of a histaminelike substance in injured skin; the underlying cause of factitious urticaria and of wheals produced by burning; and observations upon the nervous control of certain skin reactions. Heart, 1924, 11, 209.

8. Lewis, T., The blood vessels of the human skin and their responses. Shaw and Sons, London, 1927.
9. Breslauer, F., Die Pathogenese der trophischen Gewebsschäden nach der Nervenverletzung. Deutsche Ztschr. f. Chir., 1919, 150, 50.

10. Loeser, L. H., The cutaneous histamine reaction as a test of peripheral nerve function. J. A. M. A., 1938, 110, 2136.

11. Ward, A. A., Jr., Decerebrate rigidity. J. Neurophysiol., 1947, 10, 89.

12. Barron, D. H., and Matthews, B. H. C., "Recurrent fibres" of dorsal roots. J. Physiol., 1935, 85, 104.

13. Toennies, J. F., Conditioning of afferent impulses by reflex discharges over dorsal roots. J. Neurophysiol., 1939, 2, 515.

14. Toennies, J. F., Reflex discharge from the spinal cord over the dorsal roots. J. Neurophysiol., 1938, 1, 378. 